Wael Sheet

BDS, FIBMS MF (Lec.)

Mohmmed K. Hassouni BDS,F.D.S.R.C.R.S (Lec.)
Changes in Body Weight, Serum (Sodium, Potassium) and Serum Albumin after Intermaxillary Fixation in Traumatized and Obese Patients (Comparative Study)

\section{Department Oral and Maxillofacial surgery} College of Dentistry, University of Mosul

\section{Department Oral and Maxillofacial surgery} College of Dentistry, University of Mosul

$$
\begin{aligned}
& \text { الحلاصة } \\
& \text { الاهداف: هدف الدراسة اللى تقييم التغيرات في وزن الجسم ومستوى الصوديو م والبوتاسيوم وبروتين الزلال في مصل الدم للمرضى المصابين بكسور الفكين }
\end{aligned}
$$

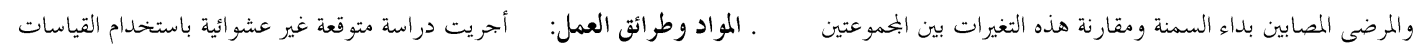

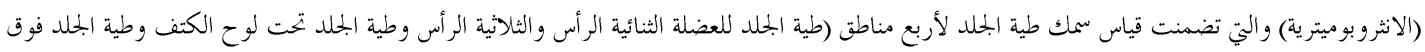

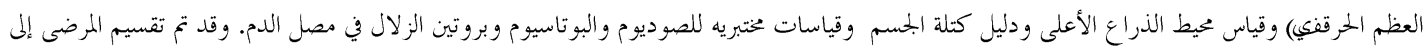

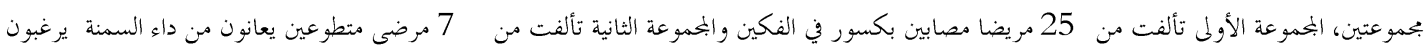

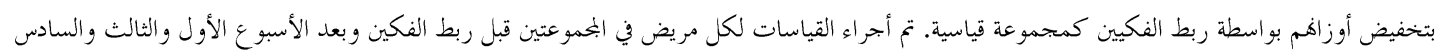

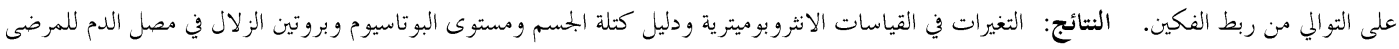

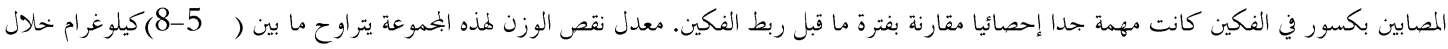

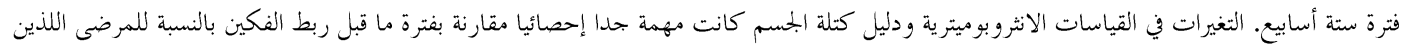

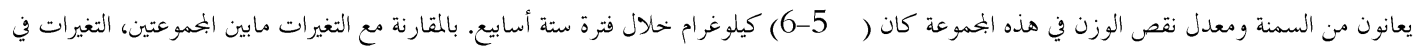

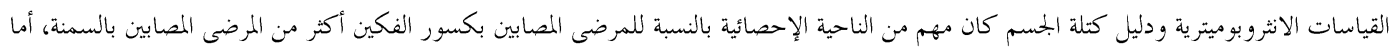

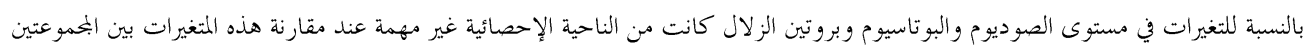

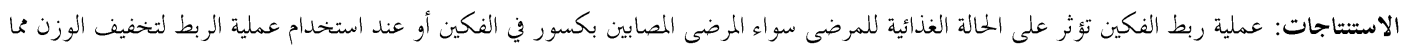

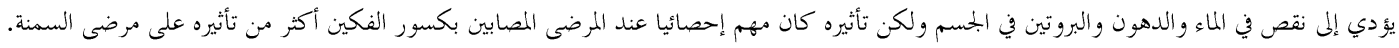

\title{
ABSTRACT
}

Aims of the study: to evaluate the effects of intermaxillary fixation (IMF) on body weight, serum electrolytes ( $\mathrm{Na}+$ and $\mathrm{K}+$ ) and serum Albumin in traumatized and obese patients and to compare the changes between these two groups. Materials and Methods: A non randomized prospective study was done. The anthropometric measurement included 4 sites of skin fold thickness (triceps, biceps, subscapular and suprailiac skin folds), upper arm circumference, body mass index and laboratory investigations to assess serum( $\mathrm{Na}+$ and $\mathrm{K}+$ ) levels and serum albumin level. The patients were divided in to 2 groups, the first group included 25 traumatized patients and the second group included 7 volunteer obese patients and IMF was placed for those patients as one of the treatment lines for their body weight reduction and were considered as the control group. The parameters were recorded for each patient in the 2 groups preoperatively, one week, three weeks and six weeks postoperatively. Paired and un paired T tests were used in the statistical analysis, a $P$ value $<0.05$ was considered highly significant. Results: The changes of the anthropometric measurements, body mass index, serum $\mathrm{K}+$ and serum albumin were statistically highly significant in traumatized patients with body weight loss ranging between (5-8) $\mathrm{Kg}$ in this group. The changes of the anthropometric measurements and body mass index in the obese patients group were also statistically highly significant with a loss of (5-6) $\mathrm{Kg}$ in body weight in this group. The changes of anthropometric measurements and body mass index were statistically highly significant in traumatized patients than in obese patients, while the changes in serum (Na+ and $\mathrm{K}+$ ) and serum Albumin level were statistically not significant between the two groups. Conclusion: IMF compromises the nutritional status of the patients leading to loss of water, fat and protein in both traumatized and obese patients but the effect more pronounced in traumatized patient due to the metabolic and hormonal response to trauma together with the limited oral intake.

Key Words: Intetrmaxillary fixation, Obesity, Body weight, Serum albumin, Na+, K+.

Sheet W, Hassouni MK. Changes in Body Weight, Serum (Sodium, Potassium) and Serum Albumin after Intermaxillary Fixation in Traumatized and Obese Patients (Comparative Study). Al-Rafidain Dent J. 2012; 12(1): 52-56.

Received: $13 / 7 / 2010 \quad$ Sent to Referees: $15 / 7 / 2010$

Accepted for Publication: 20/10/2010 


\section{INTRODUCTION}

Intermaxillary fixation or maxillomandibular fixation (IMF, MMF) is one of the modalities used in the fixation of the mandible to the maxilla after fracture reduction of these bones or any surgery to correct their position as in orthognathic surgery. The intermaxillary fixation compromises the nutritional status of the patient in the early post operative period leading to loss of water, fat and protein. ${ }^{(1)}$

The period of intermaxillary fixation which may last for 6 weeks, may be associated with many problems such as airway problems, poor nutrition, weight loss, poor oral hygiene, phonation difficulties, insomnia, social inconvenience, patient discomfort, work loss and difficulty in recovering normal range of jaw function. ${ }^{(2)}$ Most patient lose weight in IMF, a loss 6,5 $\mathrm{kg} / \mathrm{month}$ is common and may be significant in persons with inadequate general nutrition. ${ }^{(3,4)}$ While others noticed that IMF would not affect the weight changes if the patients were instructed for liquid and soft diet 4-6 time per day. ${ }^{(5)}$ IMF can also be used as co-adjuvant treatment of morbid obesity when the jaws are immobilized for restriction of oral intake. Helena concluded that IMF can be used as a presurgical solution for weight loss in preparation to bariatric surgery, improving co morbid aspects such as blood pressure, glycemia, and lipid profile. ${ }^{(6)}$ Serum albumin is the most abundant plasma protein in mammals. Albumin is essential for maintaining the osmotic pressure needed for proper distribution of body fluids between intravascular compartments and body tissues. ${ }^{(10)}$ Sodium ions are necessary for regulation of blood and body fluids, transmission of nerve impulses, heart activity, and certain metabolic functions. Potassium is a very important mineral for the proper function of all cells, tissues, and organs in the human body. It is also an electrolyte, a substance that conducts electricity in the body, along with sodium, chloride, calcium, and magnesium. Potassium is crucial to heart function and plays a key role in skeletal and smooth muscle contraction, making it important for normal digestive and muscular function. ${ }^{(17)}$

\section{MATERIALS AND METHODS}

The following materials had been used in the assessment of changes in body weight and body electrolytes $(\mathrm{Na}+, \mathrm{K}+)$ and serum albumin in traumatized and obese patients.

1-Body weight balance scale (RTZ98117), Huachao company product, made in china.

2-Body caliper. Afitness product from the caliper co.Inc,2533 N Carzon st,suit 2983Carzon City,Made in Italy.

3-Upper arm circumference flexible graduated measuring tape.

4- Body length flexible graduated measuring tape.

5- Laboratory investigations for serum electrolytes $(\mathrm{Na}+, \mathrm{K}+)$ and serum albumin.

Patients: A total number of 32 patients were included in the study who attended the Oral and Maxillofacial surgery department (Aljamhoory teaching hospital).The patients were divided in 2 groups; The first group comprised 25 patients (19 males and 6 females) who sustained fractures in the upper and/or lower jaw and needed intermaxillary fixation as an immobilization method for their fractured jaws and the period of IMF was 6 weeks. The age range was from (17-43) years with a mean of (27.7) years. Their body weight ranged between from (55-87) $\mathrm{Kg}$ with a mean of (64) kg. 21 Patients were treated under general anesthesia and 4 patients were treated under local anesthesia. The second group comprised 7 patients (6 females and 1 male), with an age ranging from (18-45) years with a mean of (35.5)years. The body weight ranged from (90-120) Kg with a mean of (101) kg.

Methods: Each patient in each group was subjected to a series of clinical examinations and laboratory investigations which included the following:

Measurements of body weight and body height. Measurements of upper arm circumference was done by using an upper arm circumference flexible graduated tape, 4 sites of skin fold thickness measurements by using a body caliper. The triceps, biceps, subscapular and supra iliac skin folds thickness were chosen for this measurement. Laboratory investigations included serum electrolytes $\mathrm{Na}+1, \mathrm{~K}+1$ and serum albumin levels for each patient. All 
these 4 parameters were recorded for each patient preoperatively (before the application of IMF) and repeated 1 week, 3weeks and after 6 weeks postoperatively.

Statistical analysis: Paired T tests were used to compare the changes in the parameters that had been used. Unpaired $\mathrm{T}$ tests were used to compare the results between the 2 groups. A $P$ value $<0.05$ was considered highly significant.

\section{RESULTS}

In traumatized patients with IMF, the reduction of four sites of skin fold thickness, upper arm circumference, body mass index, serum albumin and serum potassium was statistically highly significant during the fixation period compared with the preoperative measurements. The reduction of serum sodium was statistically non significant and shown in Table (1).

Table (1): Parameter changes during different treatment periods in traumatized patients

\begin{tabular}{lcccc}
\hline \multicolumn{1}{c}{ Time (week) } & \multicolumn{3}{c}{ Mean + SD } \\
parameters & preoperative & First week & Third week & Sixth week \\
\hline Triceps skin fold (mm) & $9.80+4.04$ & $8.18+3.35^{* *}$ & $6.98+2.85^{* *}$ & $5.60+2.35^{* *}$ \\
Biceps skin fold (mm) & $8.64+3.33$ & $7.10+2.75^{* *}$ & $5.90+2.26^{* *}$ & $5.03+2.16^{* *}$ \\
Subscapular skin fold (mm) & $14.60+6.20$ & $13.12+6.77^{* *}$ & $11.96+6.19^{* *}$ & $10.40+5.43^{* *}$ \\
Suprailiac skin fold (mm) & $18.56+9.51$ & $17.08+8.86^{* *}$ & $15.96+8.76^{* *}$ & $14.84+8.79^{* *}$ \\
Upper arm circumference (mm) & $237.44+38.7$ & $231.4+41.2$ & $233.12+39.98^{* *}$ & $231.32+39.98^{* *}$ \\
Serum sodium $(\mathbf{m m o l} / \mathbf{L})$ & $139.40+8.44$ & $139.04+7.42$ & $138.2+7.6$ & $138.28+8.15$ \\
Serum potassium (mmol/L) & $4.53+0.57$ & $4.26+0.58^{* *}$ & $4.13+0.54^{* *}$ & $4.06+0.49^{* *}$ \\
Serum albumin $(\mathbf{g m} / \mathbf{L})$ & $42.72+6.97$ & $40.8+6.39^{* *}$ & $39.46+5.98^{* *}$ & $38.58+5.74^{* *}$ \\
Body mass index & $23.32+5.0$ & $22.15+0.5^{* *}$ & $21.29+5.1 * *$ & $20.62+5.23^{* *}$ \\
\hline
\end{tabular}

** highly significant changes from preoperative data at $p<0.01$

In obese patients with IMF for the purpose of weight reduction. The reduction of skin fold thickness, upper arm circumference and body mass index was statistically highly significant during the fixation period when compared with the preoperative measurements. The reduction of serum sodium and serum potassium was statistically non significant during the fixation period. The reduction of serum albumin level was statistically significant at the first and sixth week and was statistically highly significant at the third week of the fixation period compared with the preoperative data as shown in Table (2).

Table (2) : Parameter changes during different treatment periods in obese patients

\begin{tabular}{lccc|c}
\hline \multicolumn{1}{c}{ Time (week) } & \multicolumn{4}{c}{ Mean + SD } \\
parameters & preoperative & First week & Third week & Sixth week \\
\hline Triceps skin fold (mm) & $36.43+4.76$ & $34.86+4.45^{* *}$ & $33.57+4.72^{* *}$ & $32.0+4.4^{* *}$ \\
Biceps skin fold (mm) & $30.71+6.63$ & $30.43+5.80$ & $30.71+8.24$ & $29.29+4.27$ \\
Subscapular skin fold (mm) & $37.43+4.54$ & $36.14+4.34^{* *}$ & $35.57 \pm 4.39^{* *}$ & $34.0+4.51^{* *}$ \\
Suprailiac skin fold (mm) & $42.86+2.85$ & $41.0+2.83^{* *}$ & $39.57+2.88^{* *}$ & $38.29+2.81^{* *}$ \\
Upper arm circumference (mm) & $323.0+16.22$ & $321.57+16.2^{* *}$ & $320.14+16.3^{* *}$ & $318.57+16.37^{* *}$ \\
Serum sodium $(\mathbf{m m o l} / \mathbf{L})$ & $144.14+4.3$ & $143.57+3.82$ & $142.86+3.67$ & $141.86+2.85^{*}$ \\
Serum potassium $(\mathbf{m m o l} / \mathbf{L})$ & $4.6+0.08$ & $4.30+0.25^{*}$ & $4.21+0.19^{* *}$ & $4.06+0.25^{* *}$ \\
Serum albumin $(\mathbf{g m} / \mathbf{L})$ & $38.14+1.87$ & $37.14+1.35^{*}$ & $35.86+1.46^{* *}$ & $35.86+1.22^{*}$ \\
Body mass index & $38.03+4.08$ & $37.01+4.05^{* *}$ & $36.25+4.03^{* *}$ & $35.3+4.06^{* *}$ \\
\hline
\end{tabular}

* Significant difference from preoperative data at $p<0.05$.

** highly significant changes from preoperative data at $p<0.01 .1$ 
In comparison between the traumatized and obese patients. The changes in 4 sites of skin fold thickness, upper arm circumference and body mass index were statistically highly significant in traumatized patients when compared with the changes of these parameters in obese patients. There was no statistical difference in changes of serum sodium, serum potassium and serum albumin between traumatized and obese patients.

\section{DISCUSSION}

The changes of 4 sites of skin fold thickness in traumatized patients during the fixation period were highly significant statistically from the preoperative period. This is because IMF compromises the normal oral intake which leads to a situation similar to starvation or fasting state. Fasting in a patient who is not metabolically stressed leads to preferential mobilization of fat stores and as measured by a skin fold caliper. ${ }^{(7-9)}$ In addition to the metabolic response to trauma in traumatized patients, the alteration in lipid metabolism in post stress condition favors lipolysis and this situation is not attenuated by exogenous nutritional sources and is thought to be perpetuated by a continued high sympathetic tone of catecholamine levels. ${ }^{(10,11)}$ The change in upper arm circumference was highly significant at different fixation periods due to the combined effects of limited oral intake and the stress state of the patients which lead to proteolysis and muscle wasting. ${ }^{(12,13)}$ The diet of patients with IMF is restricted on a semisolid and fluid diet which is often inadequate in energy content and in the range of nutrients and this type of diet will not compensate the proteolysis process which occurs in response to trauma. ${ }^{(14,15)}$ The changes in serum sodium level were considered statistically not significant because the effects of general anesthesia, anti diuretic $(\mathrm{ADH})$ and aldosterone leads to conservation of sodium and free water at the renal tubules. ${ }^{(16-18)}$ The changes in serum potassium were statistically highly significant because the effects of ADH and aldosterone contribute to loss of potassium at the renal tubules 3 times than in normal conditions. ${ }^{(16-18)}$ Other possible cause of decreased serum potassium include diarrhea related to irritable bowel syndrome. ${ }^{(19)}$ The changes in serum albumin levels were statistically highly significant as the diet during the fixation period was of low protein content causing a decrease in the rate of albumin synthesis. ${ }^{(7-9)}$ The increased insulin concentration as a part of metabolic response to trauma suppress the break down of muscle protein thereby depriving the liver from amino acids for albumin synthesis. ${ }^{(20)}$ The overall effects of metabolic response to trauma (lipolysis, proteolysis, muscle wasting, negative nitrogen balance and fluid loss) results in a reduction of body weight which in this study ranged from $(5-8) \mathrm{kg} /$ 1.5 month. The partial starvation state that the obese patients subjected to by IMF modifies the nutritional status. The body uses carbohydrate for energy over both fat and protein. The quantity of carbohydrate stored in the body are mainly glycogen in the liver and muscles and can supply the energy for only half a day. After a few hours of starvation there is progressive depletion of tissue fat and protein. ${ }^{(16,17,21)}$ The changes in the level of serum sodium was statistically not significant in obese patients because the diet that had been taken during the fixation period was restricted on liquid form which contained normally adequate concentrations of sodium ion. The changes in serum potassium levels were statistically significant in the obese patients and this may be due to the intake of a diet which is inadequate of potassium ion or due to its loss from the gastrointestinal tract. ${ }^{(22)}$ The changes in serum albumin level in obese patients were statistically significant. Gluconeogenesis decreased from one third to one fifth its previous state because the body will depend on ketone bodies in the liver to supply energy for the vital organs. This will offer the essential amino acids for albumin synthesis in the liver. ${ }^{(23,24)} \mathrm{A}$ loss of $(5-6) \mathrm{kg} / 1.5$ month occurred in this group of patients. The percentage of difference in parameter changes between traumatized and obese patients were statistically significant in the traumatized group because the combined effects of trauma, general anesthesia and the partial starvation state potentiates each 
other that affects the general nutritional status of the patients.

\section{CONCLUSION}

Intermaxillary fixation compromises the nutritional status of patients during the fixation period leading to loss of water, fat and protein in both traumatized and obese patients but the effects more pronounced in the traumatized group with a loss of (58) $\mathrm{kg} / 1.5$ month of body weight and a loss of (5-6) kg/ 1.5 month of body weight occurring in obese patients. The anthropometric measurements and body mass index appeared to be reliable indices in monitoring the nutritional status of the patients with IMF. The significant changes in serum potassium levels during the fixation period in traumatized patients necessates special attention regarding monitoring and supplementation of this electrolyte during the fixation period.

\section{REFERENCES}

1. Worrall S. Changes in weight and body composition after orthognathic surgery and jaw fractures. Brit $J$ oral maxillofacial Surgery. 1994; 23(5): 289-92.

2. Adel R. A treatment protocol of mandibular fracture. $J$ crainomaxillofacial surgery. 1996; 2:27-30.

3. Williams JL, Murley R. Maxillofacial injuries. 2nd edition. Churchill livingstone.1994;Vol.1. Pp: 60-63.

4. Williams J L, Murley R. Maxillofacial injuries. 2nd edition.Churchill livingstone .1994; Vol: 2. Pp: 818-820.

5. Tudsri S, Rohrich R J. Weight changes in patient with intermaxillary fixation. Int J oral maxillofacial Surgery.1999; 22: 87-91.

6. Helena S, Daniela R. Obesity surgery.2nd edition. Mosby.2004; Vol.2. Pp: 829-832.

7. Cuschieri A, Steele RJ. Essential surgical practice. Module 9. 4th edition, Reed educational and professional publishing .2000; Pp: 234-240.

8. Cuschieri A ,Steele RJ. Essential surgical practice. Module 4. 4th edition, Reed educational and professional publishing .2000; Pp: 89-95.

9. Cuschieri A, Steele RJ. Essential surgical practice. Module 8. 4th edition,
Reed educational and professional publishing. 2000; Pp: 219-222.

10.Lyons F, Meeran K. The physiology of the endocrine system. J clinical anesthesiology. 1997; 35: 16-21.

11.Edward Lin, Stephen F. Endocrine and Metabolic response to injury. Principles of surgery. 6th edition. McGraw-Hill book Company. 1999 ; p: 42-50.

12.Gibson SR. Principles of nutritional assessments by anthropometric measurements. First edition. Mosby. 1990; Pp 88-95.

13.Tepsake R. Immunonutrition, J current anesthesiology, 1997; 10: 86-91.

14.Gatley M , Mullin T. The team approach to intermaxillary fixation. $J$ Advance clinical care. 1990; 6:24-5.

15. Harju E, Parnu H. Weight changes after jaw fixation due to sagittal split osteotomy. Brit J oral surgery. 1975; 12(3): 187-191.

16.Guyton. Metabolism \& temperature regulation. Medical physiology. 10th edition. W.B. Saunders company. 2000; Pp: 866-867.

17.Guyton. Body fluid and the kidney. Medical physiology. 10th edition, WB. Saunders company. 2000; Pp: 432-435.

18. Desborough JP. Physiological response to trauma and surgery. Foundation of anesthesia. 2nd edition. mosby. 1999; Pp: 713-720.

19. Shephard B, Townsend GC. The oral effects of prolonged intermaxillary fixation. Int J oral surgery. 1982; 1(5): 192-194.

20.Heatley RV, Green JH, Losowsky MS. Basics in clinical nutrition. Consensus in clinical nutrition. Cambridge university press. 1994; Pp: 75-77.

21.Benyon S. Metabolism and Nutrition. 2nd edition. Mosby. 1998; Pp:54-57.

22. Charytan D, Golfd DS. Indication for hospitalization of patient with hyperkalemia. Arch internal medicine. 2000; 160(11): 1605-1611.

23. Brad AR. Human albumin administration in critically ill patients. Brit medical J. 2003 ; 317(7153): 223-4.

24.Bjorvel H, Hadell K, Jonsson B. Long term effects of jaw fixation in sever obesity. Int J of obesity. 1999; 8(1):79-86. 